\title{
AFTER THE RELATIONAL TURN: \\ THE PROBLEM OF SOCIAL IDENTITY
}

Irena Szlachcicowa

University of Wrocław

Social scientists have been attracted to the problem of identity for a long time. The question of identity, with its inevitability and simultaneously problematic nature, is considered to be a sign of the times in which we live. The discourse regarding new forms of identity has dominated most theoretical debates held in the last two decades of the twentieth century. Scholars' increased interest in these issues is associated with the social changes that have noticeably transformed the contemporary world. Identity, and the various forms of its metamorphosis, have been treated as a litmus paper for grasping changes in mentality caused by the transition from a modern to a postmodern society.

Sociologists have made many theoretical and empirical studies of the notion of both individual and social identity. Conceptual studies and research projects have not only enriched our knowledge in this sphere but also demonstrated the problems troubling sociologists. Treating identity as a research object stimulates us to pose again questions about the nature of social reality and the relation between individuals and society. Identity is described as a process and its occurrence and existence require reference to other people and the world. These two features-processual and relational nature-prove to be especially useful in rendering the specificity of the phenomenon of identity. They are also considered to define the relational approach, which solves the theoretical dilemma between the individual and society by choosing a third path, exposing relations as the main constituent of social reality. 


\section{/// The Relational Turn: Old Questions, New Prospecting}

Twenty years ago, Mustafa Emirbayer published his manifesto of relational sociology. Looking back, we see a path of theoretical inquiry that makes us realize aporias and the recurring questions about the nature of the social world. The relational turn seen in sociology in recent years is worth being treated not only as another turn taking place in the humanities but also as an expression of theoretical self-awareness and the search for sociology's identity. The relational nature of reality is increasingly recognized by sociology, which therefore acknowledges what the substance and subject of its research has been for a long time, if not always.

Relational thinking is an alternative attitude to both functional structuralism and strongly individualistic theories (self-action theory), and as such, questions the theoretical schemes dominant in sociology and the resulting models of research practice. Relational sociology emphasizes the processual and emergent nature of reality. As a result, social phenomena and patterns of action can only be recognized in the process of it happening, and not by a static and simplified cause-and-effect scheme. Actions - individual and collective-appear as successive stages of the specific process of events, and are the result of the configuration of relations and the social interactions constituting a particular situation. Relational theory rejects substantialism and focuses its attention on the complexity and dynamics of all forms of social life, the mutual relation between reality and the knowledge acquired from it, and the subjective character of action.

The relational approach aims to move beyond the dichotomy between the individual and society, which has been over-exposed in sociology, rejects all forms of social determinism, and essentially redefines the very concept of the individual. Analytical development of the relation between the cultural and structural dimension and human agency provides a new concept of the individual as a reflective acting subject. Relational thinking about individuals and their activity is based on the concept of a dialogic self. A dialogical self is seen as a specific and necessary condition for action. The ability to act is shaped by internal conversations on the cognitive, moral, and social levels.

\section{/// The Dialogical Self}

The genesis of the dialogical self can be found in pragmatism. Using the distinction proposed by George H. Mead, we can point to two ways 
of describing the self in pragmatic theory. In the first approach, represented primarily by William James and Charles H. Cooley, the self is treated as a special kind of emotion ("self-feeling"). In the second approach, described as reflective and developed by Charles S. Peirce, John Dewey, and Mead, the self is cognition, the main focus here is on self-consciousness as the basis of self (Wiley 2006: 6).

A pragmatically oriented sociological theory of the self accepts the concept of man as an acting subject. The dialogic character of the self is perceived as a specific and necessary condition of action; the internal conversation gives the actions desired direction and allows for their monitoring. In Mead's concept, the self is a dialogue between " $\mathrm{I}$ " and "Me" in which the individual adopts the attitude of "generalized other" to himself. The dual nature of the self that manifests itself in the structural relationship of "I" and "Me" reflects the union of individual and society. "Me" is the self seen as the object of the immediate past, which Mead referred to as the earlier form of "I." "Me" represents a reference to society; it is a set of determinants and expectations stemming from social relationships and group identification. "I" represents the individual's response to socially imposed conditions. It expresses the individual capacity for creative and spontaneous action, and reveals the aspect of the individual self that escapes social determination and remains indeterminate.

The concept of a dialogical self was interestingly developed in Peirce's semiotic theory. Peirce addresses the issues of human subjectivity by explaining both mind and selfhood in terms of semiosis - "sign-activity." The reality in which man lives is a reality of significance; the world of signs thus constitutes all forms of human thought and action. In the deepest layers of his self, man is a form of semiosis. In Peirce's concept the inner conversation takes the form of a dialogue between the different phases of the ego. Self as a process of character activity goes through three phases and corresponding temporal references (Archer 2003: 71). "Me" has a reference to the past; "I" is a self located in the present time, which takes up the dialogue with the future "You" as the projected mind. Peirce defines "You" as "that other self that is just coming into life in the flow of time" (Wiley 2010: 18). The pre-existing self is indispensably preceded by the (dialogical) activity that transforms it, and the new form of self is necessarily later than that activity. None of them interfere with the continuity of time. Past-related "Me," which is referred to by Peirce as a critical self, is essentially composed of habits_-of predispositions to react in certain ways under certain circumstances (Archer 2003: 72). Ability to act is the result 
of a mediation between the present "I" and the projected, future "You," which is manifested in the inner dialogue.

\section{/// The Human Being as Relational Subject}

For many years, Margaret S. Archer has been developing and improving the theory of social morphogenesis. The conception of a person as an agent constitutes a significant part of this project. The individual's subjectivity is presented as the answer to both structural factors and the agency attributed to the individual. In conceptualizing the person, Archer adopts as a starting point the thesis that "our sense of self, as part of our humanity, is prior and primitive to our sociality" (2000: 121). According to Archer, referring in the first place to the category of humanity and not to socialization plays a key role in explaining human agency and the theoretical study of relations between the individual and society. Humanity, understood as the features and strengths that are characteristic of people, was presented as prior and autonomous in regard to society. The features distinguishing human beings are universal, emergent, and remain in relation with the world.

They are relational: stemming from the way our species is constituted, the way the world is and the necessity of their mutual interaction. The relations between the two, being universal, supply the anchor which moors our elaborated human forms as Selves, Persons, Agents and Actors, and thus sets limits to their variability (Archer 2000: 17).

Hence, a human being is not reduced to a social being, and the effect of socialization is always derivative in regard to what is sui generis human. The self, as emergent and relational, is formed in interaction with the world. Importantly, human presence in the world is not defined solely by the social. A person interacts with three orders: natural, practical, and social. Archer attributes special meaning to the social praxis, because it contains the source of the human sense of self. The ability to think, self-awareness, and the continuity of the sense of self emerge from embodied practical actions. The continuous sense of self, being an effect of an individual's practical experiences, has a pre-discursive character and as such does not depend on participation in social conversation. The embodied self, created in interaction with the material environment, constitutes the basis for 
human personality and enables the development of an individual identity, which in turn precedes the creation of a social identity. The condition for the formation of an individual identity is thus the feeling of a continuity of identity: seeing oneself from a biographical perspective always as the same person with the simultaneous feeling of one's distinctiveness from others. The conception presented by Archer treats a human being, like reality, as being layered in the ontological dimension. The process of identity-forming and human subjectivity is emergent; it takes place through revealing subsequent layers — self, person, agent, and social actor.

The shaping of personal identity is strictly dependant on reflexivity as an inseparable attribute of human beings. The innate predisposition to reflect upon oneself and the external world distinguishes and defines human beings. The dialogical self constitutes a personal, characteristic feature, which has emerged in the evolution of the human species. It depends on-even though it is not reducible to-the biological existence of a person. The silent posing of questions to oneself and looking for answers, wondering about oneself and different aspects of the social environment in their mutual relations, are decisive for reflective internal dialogue (Archer 2007: 63). Reflexivity is a universal feature: as a specific mental activity it occurs in all people, but in individualized shape. Its form depends on individually experienced concerns and interactions, in the broad sense, with the world. The mechanism of human reflexivity is practically expressed in internal conversation. The internal dialogue reflects the range of human concerns resulting from references to the natural, practical, and social order, and the emotional commentary on them. The ability to develop the concerns emotionally has been particularly emphasized here. According to Archer, this dimension of human existence-which theoreticians had for many years erased from reflection on human actions - constitutes a necessary element of the formation of individual identity. Emotions as an irremovable element of humanity constitute the core part of people's internal life because they are the driving force of internal conversations (Archer 2000: 194). Human presence in the world is marked by concerns, which result from humans' relation to the world, other people, and plans and actions, and which enable them to define who they are, what they want, and what they hold dear. Only the hierarchization of objects to which we refer, from the perspective of what is important to us, reveals our ultimate concerns and accompanying emotions. Reflective development in internal dialogue of what we see in life as important and what we care about determines the crea- 
tion of identity, "our reflexivity, which is part and parcel of our human consciousness, defined our personal identities by reference to what is of ultimate concern to us in the world" (Archer 2003: 33).

Personal identity, being logically and ontologically prior to social identity, conditions its occurrence but also remains in dialectical relation with it. In order to form a social identity an individual must first have a personal identity, which is not only prior but also more extensive than a social identity since the former activates the latter and defines its role in respect to other dimensions of life. Personal identity, understood as a reflexively developed constellation of ultimate concerns, intertwines in dialectical relation with the social identity, that is, the ability to be a social actor, performing specific roles. Thus what is external (social) is connected with what is internal (subjective).

Internally, it is through self-talk that we define our ultimate concerns and thus our personal identities, since our singularity as persons is constituted by our particular constellation of concerns. Externally, we first seek to realise these concerns in society through further inner dialogue which identifies those roles through which they can be expressed. Afterwards, we seek to acquire the roles in question. Finally, our social identities arise from the manner in which we personify such roles in line with our concerns. In other words, internal conversation is not "idle"; one of its most important causal powers is reflexively to conceive and to conduct those courses of action by which we navigate our way through the social world (Archer 2007: 64).

Becoming a social actor, able to take specific actions within social roles, is a complex process of interactions between the human self and activity, which leads to the emergent social identity. The motive power of this process is the reflexivity of active subjects, which demonstrates itself in the ongoing internal conversation. The internal dialogue shows how the social context and cultural context, with the objective circumstances of action imposed by it, are confronted with the subjective conceptions and aspirations of an individual. The self, and the personal self constructed on its basis, constitute the human powers that lead-next to the emergent structural and cultural features - to the emergence of agents and social actors.

The formation of social identity conditions not only the fact of taking on a specific social role but its personifying through a given individual's 
involvement and specific way of performing it. The personifying of a role means more than the performing or acting of the role since it has personal reference. For that reason, social identity may be seen as derivative from personal identity. The formation of a personal identity determines the emergence of a social identity, which in turn influences the shape of the personal identity. The mutual influence of social and personal identities leads, according to Archer, to a synthesis within which both forms of identity are emergent and distinct but at the same time "contributed to one another's emergence and distinctiveness" (2000: 288). The process of acquiring social identity is presented by Archer as progressive individuation based on the emergence of individual self-awareness. This means that the activating element of social identity is the formation of a continuous sense of self ("I"). While the self-as-object ("Me"), which refers to the past, is a self unintentionally located within the social distribution of resources as the Primary Agent. In turn,

The "We" represents the collective action in which the self engaged as part of Corporate Agency's attempt to bring about social transformation, which simultaneously transformed society's extant role array as well as transforming Corporate Agency itself. This then created the positions which the "You" could acquire, accept and personify, thus becoming an Actor possessing strict social identity (Archer 2000: 294-295).

The differentiation between personal and social identity plays a significant role here, since it enables us to build arguments against the diluting of humanity in social theory. On the one hand, by defending humanity, Archer opposes the sociological imperialism that reduces the individual to what is social, as well as the modern idea of man, promoting individualism and instrumental rationality. Both approaches, in her opinion, cannot meet the task of creating a social theory that explains the problem of human agency. According to Archer, the only chance for the revival of social theory is a new conception of human beings-one that will fully render the autonomy of human motive powers but at the same time will not completely reject structural and cultural factors.

Pierpaolo Donati continues and at the same time extends the concept of the human being as a subject presented by Archer. All the things the two authors share can best be seen in their joint work The Relational Subject. Both Archer and Donati develop their theories based on the assumptions of 
critical realism. The perspective of critical realism plays with the relational perception of social reality. The social structure and individual actions are two interactive and co-dependent but ontologically different levels of social reality. Social ontology, according to critical realism, is based on the reality of social structures, which are defined "as relations between social subjects as the effect of social positions which they occupy. The structures have causal effect, both enabling the actions which otherwise would not be possible (...) and limiting them" (Benton \& Craib 2003: 154). The structural factors have their own reverse in the form of the dependency of the social structures on individual and social agency, which means the ability to individually transform the existing structures. Critical realists aim at circumventing reductionist tendencies which conceal both methodological individualism and structural determinism.

By naming his theoretical stance "relational sociology," Donati unambiguously underlines that he does not see relations as prior to human consciousness (see Donati 2011). He clearly dissociates himself from both subjectivism and the theories labelled as objectivist, which include also relationalism. ${ }^{1}$ He thinks that human consciousness and relations are ontologically separate and autonomous entities, mutually creating each other. The nature of consciousness, as of all other phenomena, is relational. This means that a man is a subject who has the ability to choose who and what he cares for, but at the same time he can do so only through relations with others (Donati 2016: 353). Awareness of man's relational nature emerges in the process of mutual influence between the individual consciousness and external environment at various moments of time. Human beings, which are understood by Donati as "relational subjects," may be recognized and understood thanks to the fact that they remain in relation to others and the world. Their identity and ability to act stems from their relations, which in turn are reflexively processed by them.

The term "relational subject" indicates individual and social subjects in that they are "relationally constituted," that is, in as much as they acquire qualities and powers through their internal and external social relations. The term "relational subject" refers to both the individual subject and the collective (social) subject as

\footnotetext{
Donati makes a clear distinction between the European relational sociology that grew out of critical realism and the relational approach represented by $\mathrm{H}$. White or M. Emirbayer, whose genesis is to be found in network theory. That is why Donati distinguishes between relational sociology and relationalism, which he considers to be a reductionist approach that recognizes the ontological priority of relation to consciousness.
} 
regards the role that the relation with the Other plays in defining and redefining one's own identity, whether personal (the identity that the I has of itself) or social (the identity that the I has for Others) (Donati 2016: 355).

The notion of relational subject introduced by Donati has its individual and collective reference. The individual relational subject is reflected in the process of constructing the internal self-definition of a person, since the individual self is shaped in relation to itself and to the world. The relational recognition of collective subjects is more problematic. Here the introduction of the "We-relation" as a reflexive reference to others proves to be helpful. Recalling the assumptions of relational realism, Donati modifies the definition of reflexivity suggested by Archer. And the relational reflexivity of the collective entity means "the regular exercise of the mental ability, shared by all (normal) people, to consider the influence of their relation(s) with relevant others on to themselves and vice versa" (ibid.). The condition for the occurrence of the relational subjectivity of an individual or collective is individual identity, shaped in the network of social relations and defined reflexively through the involvement of individuals.

Individual identity, which is relational in essence, has temporal and spatial location. Space means here not only the possibility of referring to a specific place but primarily the social and cultural context, which defines the awareness and acts of an individual. The relational subject comes from the network of relations as the effect of actions completed in a specific social context. In the actions taken, social and cultural structures are activated and reflexively embedded in life by agents. Thus identity, both personal and social, is recognized in relation to its social environment. Social relations as sui generis reality are defined by Donati in the optics of realism, by their ontological distinctiveness from the individual and the social structure. Relational reality, which emerges from actions and human agency (as distinct and having its own causal powers and specific properties), "is activity-dependent, but has its own structure, the exercise of whose causal powers acts back upon the constituents (ego and alter) of the relation itself" (Donati \& Archer 2015: 55-56).

In accepting the morphogenetic theory developed by Archer, Donati suggests some modifications. He uses the concept of self-development proposed by Archer as a starting point, and suggests the intersection of its model of self-forming with the Parsons AGIL scheme. To put it briefly, in existing between nature and transcendence, in the process of self-devel- 
opment a human being progresses through the following phases: a subject or potential self ("I"), through the experience gained in social practice, becomes a primary agent ("Me"), then a corporate agent ("We"), to eventually become a social actor ("You"). ${ }^{2}$ The maturation of the self, as a dialectical relation between the first and last phase ("I"/"You"), is a cyclic process of transition from phase to phase and is accomplished through an internal dialogue at each stage. As a result, the formation of the human self is determined not only by the experience gained in the practical sphere, but also by the ability to cope with the transcendent dimension. Because of the transcendent dimension, the individual surpasses the natural order and becomes a social actor capable of personifying his roles. The overcoming of the natural and social order occurs in moments of reflection, in the inner dialogue of the self. A relational view of identity and its ability to act subjectively at all levels of social reality requires perception of the individual as a reflective being. Reflectivity, which takes the form of internal and external conversations about interpersonal relationships, generates the ability to initiate joint actions.

\section{/// The Relational Self by Kenneth Gergen}

Kenneth J. Gergen takes a completely different stance. The different perception of the problem is connected in the first place with the adoption of different ontological assumptions. Here we are dealing with clear support for social constructionism. Socially created reality occurs as a result of individual and collective actions which constitute it and give it meaning. Adopting this constructionist attitude Gergen states that all claims toward truth and rightness are mere social constructions. Social constructionism assumes that as much as there is no single-essentially objective-reality, there is also no single, true reproduction of such a reality. Finding reality and how it functions is possible solely from some socially specific perspective. In consequence, the researcher's attention is focused not on the correct presentation of reality, showing or rather revealing its true face, but on the process of the social construction of its image. The object of cognition thus is not the reality as such but how it is perceived in the social conscience.

Gergen promotes a discursive perception of the human self, developed on constructionist assumptions, while at the same time questioning the individualistically oriented modern theories that emphasize the intentional

2 Donati's self-development cycle is analogous to that described by Archer. 
nature of human actions. The form of self he assumes-which is dialogical and discursive in its essence-is a result of a broadly understood process of individual socialization. In the most general terms, the human self is shaped by socialization, within which an introduction to the sphere of language takes place, i.e., appropriate structures of meaning. Learning how to use language as the basic form of communicative action is a condition for the creation of the self. The self-contemplative self-awareness-manifests itself in the ability to define itself in conversation with others. The dialogical nature of the self is expressed in narrative, which always has subjective and contextual references. Identity, as a phase of individual selfawareness, is constructed and reconstructed in language. Hence, Gergen's identity comes down to language construction, which is situationally created and manifested. Narrative identity is the process of getting to know, name, and feel oneself, which takes place through the ability to tell stories about oneself and others. Importantly, the self as a narrative told by an individual may assume different shapes in different social contexts. The process of creating identity depends on the one hand on semiotic patterns imposed on the individual by the language and on the other constitutes a reflection of the wide context in which the conversation takes place. The conversation - including its specific form, the internal dialogue-is always of a relational character.

The condition of the postmodern world is described by Gergen in the context of cultural changes, the rapid development of technology, and the exceeding saturation of social relations. Postmodern culture, by setting the individual free from the normative limitations of effective socialization and the requirements of the social order, treats it to uncertainty, reflexivity, and an excess of doubt. The world, demystified of modernist assumptions about man, community, and ethos, ceases to be a real one. Reality is superseded by a construction of reality, and as everything else, becomes a language artefact. The feeling of self, inconsistent and problematized, continues to multiply new questions about identity instead of creating it. When faith in reality and the objective nature of reality is undermined and doubt is cast on the integral image of the individual, "then daily existence as an objectively given self is threatened" (Gergen 1991: 137). The multiple perspectives from which we see reality shows us its relative nature and blurs the identity of both people and things. In The Saturated Self: Dilemmas of Identity in Contemporary Life, Gergen analyses the impact of the saturation of human contacts on the perception of individual identity and the way it is conceptualized. As he emphasizes, what largely stimulated the direction of 
this theoretical interest was his "admiration for the contribution of social saturation to democratic expression" (Gergen 2000: xvi). The ongoing increase of social saturation changes the individual's self-awareness and the character of social relations. Social saturation means the intensification of possible identifications and, due to the blurred borders, the awareness of their constructed character.

The changes taking place in postmodern reality force us to renounce the earlier patterns of perceiving the human self. ${ }^{3}$ They make us realize that notions and previous ways of perceiving the individual self are not valid anymore. The transition from modern to postmodern society is defined by Gergen as abandoning the concept of an individual "I," which can be identified and perceived as an autonomous whole. Earlier conceptions of the self, both romantic and modernist, treated the individual as an autonomous subject. Redefinition of assumptions about the individual self shows, in the first place, the blurring of its internal, individual character in a vast network of social contacts. Caught in a constantly expanding network of social relations, an individual spends his or her entire time and energy on the creation and maintenance of social relations. The individual self becomes partial and incomplete since it is constantly filled with inconsistent conceptions about itself. Identity cannot be treated as stable and existing in a given shape anymore; in consequence, our identity is not given but " is continuously emergent, re-formed, and redirected as one moves through the sea of ever-changing relationships" (Gergen 1991: 139). This causes abandoning individualistically oriented thinking for the conception of relational identity.

Gergen presents the blurring of the individual self as a two-stage process from which the relational "I" emerges. The modernist faith in the self becomes weaker under the influence of a stronger awareness of dramatic identity-creation practices. Due to our possible diverse identifications of ourselves, our identity is no longer in the centre but is replaced by the way it is created. Thanks to the awareness of self-construction, the conception of an authentic " $\mathrm{I}$ " is much weakened. Identity is treated instrumentally as a correctly chosen mask for expressing oneself at a given time. Gergen calls this stage "strategic manipulation." The game in which we construct our

\footnotetext{
Gergen distinguished three stages in the conceptualization of the human self: the romantic "I," modernist "I," and postmodernist "I." The romantic self is characterized by the tendency to full, emotional involvement in relations with others and the world. The modernist "I" is rational; an individual's actions are predictable, honest, and just. In contrast to the earlier conceptions, the postmodernist "I" is chaotic and inconsistent (1991: 6-7).
} 
numerous identities results from social saturation and leads to the creation of a "pastiche personality."

The pastiche personality is a social chameleon, constantly borrowing bits and pieces of identity from whatever sources are available and constructing them as useful or desirable in a given situation (Gergen 1991: 150).

As a result of the ongoing change, identity comes down to self-presentation and stylization of oneself. This is another stage of constructing the relational self. When identity is in the first place an advertising effect, it becomes more and more liquid, and the border between the authentic " $\mathrm{I}$ " and the constructed image disappears. Then the individual self is replaced by a relational reality in which " $\mathrm{I}$ " is transformed into " us" (ibid.: 156). When the sense of the self as a synonym of the autonomous individual becomes completely blurred, the self becomes a manifestation of numerous forms of co-dependence and social interactions.

As the self as a serious reality is laid to rest and the self is constructed and reconstructed in multiple contexts, one enters finally the stage of the relational self. One's sense of individual autonomy gives way to a reality of immersed interdependence, in which it is relationship that constructs the self (Gergen 1991: 147).

The process of individual identity construction reflects much more the impact of social surroundings than its inside. Identity-its shape and whether it will be recognized-constitutes an element of a social game in which the individual participates. This happens mainly through the intersubjective and relational character of language. The construction of "I" takes place not so much through the language but within the limitations set by it. Language cannot be seen as an instrument that enables us to show internal reality.

Thus, individuals are not the intentional agents of their own words, creatively and privately converting thoughts to sounds or inscriptions. Rather, they gain their status as selves by taking a position within a preexisting form of language (ibid.: 110). 
People experience reality thanks to their existence in language. Seeing the world and oneself is always language-mediated and requires entering the discourse. The ability to use language not only determines human interactions but also constitutes an indicator of the existence of the human self. Identity is a narrative and nothing more. It is wrong thus to assume that language solely expresses our internal "I" since we-when speakingcreate the self. Hence, Gergen refers directly to notions of discourse when characterizing the process of self-construction. He presents three ways of seeing the self: firstly, the self as discursive action; secondly, discourse of the self as performance; and thirdly, discursive action as relationally embedded (see Gergen 2011).

Relational theory, in order to get rid of the troublesome burden of essentialism in understanding the human self, emphasizes the processual nature of reality. Gergen, recalling the philosophy of Ludwig Wittgenstein, believes that words of a given language gain their meaning by their use in human interactions. He emphasizes that re-conceptualization of the self as emergent and relational requires a different language perspective. $\mathrm{Ob}-$ serving the difference between the action itself and the acting subject, he claims that in interpretation we should make an effort to unearth actions from the domination of a person: "it is a difficult task to eliminate the doer behind the deeds" (Gergen 2011: 112). Only the emphasis placed on the demonstration of actions taken by an individual when acting makes the relational context visible, both of actions taken and of the self emerging from them.

\section{/// Narrative Identity}

In the 1990s Margaret R. Somers also perceived the need to introduce changes in the theoretical recognition of identity. She sees the problem of redefining identity in combination with a politics of identity - which is more and more often included in the scholarly discourse-and increased interest in social constructionism. As she emphasizes, analysing identity currently plays a crucial role in explaining the problems of human agency. Despite noticeable differences between what Somers suggests and Gergen's stance, both approaches understand the question of identity in a way that is relational and clearly connected with narrative. It is the narrative nature of identity that is decisive for Somers. The attractiveness of the narrative conception of identity results, in her opinion, from the fact that it enables the limitations of narrativism and previous ways of conceptualizing identity to 
be overcome. The most common weakness of existing identity theories, according to her, is researchers' tendency to over-favour the substantialist approach to the object of their research. Often, an unintended tendency to define identity by single, strict categories, such as race, class, or gender, threatens us with falling into the essentialist perception of reality. This is a recurring cognitive limitation, which gives us a deceptive certainty and leads to unnecessary simplifications. An effective way to avoid these mistakes is to define identity as a complex system of identifications, which has clear situational and temporal reference.

One way to avoid the hazards of rigidifying aspects of identity into a misleading categorical entity is to incorporate into the core conception of identity the categorically destabilizing dimensions of time, space, and relationality (Somers 1994: 606).

The concept of identity presented by Somers, combining the relational character of human actions with narrative, offers a new perception of the ontological and epistemological dimension. Narrative is not seen here solely as a different research method but is considered to be a factor constituting the human self. Only analysis of identity in the narrative approach enables us to grasp the process of its construction in the historical and empirical aspect. Thanks to the ability to create narratives about the world and oneself, people find sense in what they do and discover who they are, "it is through narrativity that we come to know, understand, and make sense of the social world, and it is through narratives and narrativity that we constitute our social identities" (ibid.). The assumption that both reality and knowledge about reality have a relational character leads to an understanding of identity as deeply rooted in the network of intertwining social relations, which change in time and space.

The process of identity-construction in the narrative perspective shows the merger of biographical stories with life itself on the ontological level: "social life is itself storied and that narrative is an ontological condition of social life" (Somers 1994: 613-614). The creation of identity and the awarding of meaning to what is experienced are always narratively mediated. This equation of identity and narrative means that people identify themselves and objects of the surrounding world, thus creating a repertoire of private and public narratives. Narratively created identities place people in the discourse, which imposes a certain "causal emplotment" of life experiences and their understanding, while at the same time setting 
the direction of human actions. Narrativity shows human agency not as "universal agency," but as the effect of an individual's participation in discourse. The reference to a person and the narrative created by this person makes it possible to avoid treating human actions as conventional, and makes it more difficult to use reifying categories, in the form of unambiguous cultural and gender identifications, to define individual identity. The narrative as a configuration of relations set in the context of time and space is a fictionalized story connecting individual events in a meaningful whole. The plot of the story shows a set of mutually related events-an arrangement in which certain events result from others, constituting their obvious or presumptive reason. The relation does not render a chronological order of events; the bonding element of the story, which makes it consistent and comprehensible, is the plot. The fictionalization of the story determines its narrative potential, "turns 'events' into episodes" (ibid.: 616), gives meaning to individual events, and merges and changes their character. Thanks to this, understanding of social actions does not take place through their categorization but in a way emerges from the context of the episodes told. This happens because the story, in its background, shows events in their historical and relational references.

Narrativity manifests itself in four forms: as ontological narratives, public narratives, conceptual narrativity, and meta-narrativity. "Ontological narrative" affects human consciousness, opinions, and actions but at the same time is itself influenced by them. Through it, people recognize sense in their existence. People's setting in discourse shows them how they define themselves and their existence in the world:

Ontological narratives are used to define who we are; this in turn can be a precondition for knowing what to do. This 'doing' will in turn produce new narratives and hence, new actions; the relationship between narrative and ontology is processual and mutually constitutive. Both are conditions of the other; neither are a priori (Somers 1994: 618).

At the level of ontological narrative, the events become episodes, which are the material for narrative. Hence, the narrative about life does not come down to a set of separate events but is one narrative about somebody in relation to what is beyond this person. Ontological narratives, which are social and interpersonal in their character "can only exist interpersonally in the course of social and structural interactions over time" (ibid.). Social ac- 
tors entangled in networks of mutual relations adjust the narratives to their identities just as they adjust the reality to their narratives. "Public narrativity" includes narratives (micro- and macro-stories) related to the cultural and institutional dimension of social communities. "Meta-narrativity" signifies narratives referring to the main social discourses and processes in which we participate both as members of contemporary societies and as sociologists. "Conceptual narrativity" includes notions and explanations created by sociologists in their research. It is aimed at the creation of a new theoretical language, which will enable us to reconstruct ontological and public narratives created by specific social actors, including their historical nature and set of relations with broadly understood surroundings. Conceptual narrativity is understood by Somers as a merger of narrative identity with a relational setting, and she sees this dimension of analysis as decisive. She justifies it with the necessity to make a significant notional change at the level of defining the object of research. Due to the assumption that social reality is created by narratives, the goal of cognition becomes "to capture the narrativity through which agency is negotiated, identities are constructed, and social action mediated" (Somers 1994: 620).

The concept of narrative identity integrated with the relational setting enables us, according to Somers, to abandon dualist, "subject-object" thinking, which is hampering the development of social theory. Identity defined as the effect of a network of social relations constitutes the transformation of this dichotomy in numerous matrixes of relations correlated with the impact of political power, social practice, and public discourse. Somers emphasizes that the claim for a re-conceptualization of the option of identity matches "identity politics," which have been much discussed in recent years. The question of identity's involvement in politics, which is particularly visible in relation to groups that are marginalized in the political and social sphere, reveals new forms of political activity. This involvement shows the aspiration of different groups for social recognition of their identities - as is being increasingly clearly articulated in the public discourse. The political involvement of identity groups related to gender, religion, culture, ethnicity, or any other dimension of social reality, is the expression of an attempt to recover suppressed subjectivity. The politicization of identity, by generating new research questions, stimulates us to revise the theories and interpretative patterns developed in this area of research. The previously used conceptual apparatus is currently seen as oppressive and thus inappropriate for an adequate description of reality. This leads to the need to develop a new theoretical language: "new words" 
able to eliminate the limitations of the prevailing discourse. Having been introduced to the political game, the notion of identity may easily become distorted. Group identity is articulated thus in defence of identity and in confrontation with otherness. As practice shows, this often leads to the creation of totalizing fictions and risks the production of a categorical description of group identity (ibid.: 610). These new theoretical challenges are seen by Somers as a breakthrough, since they make it possible to abandon essentialism, which is still present in identity theory, and to introduce a relational and historical conception of identity in place of rigid attributive categories.

\section{/// Conclusion}

In the achievements of sociological theory we can easily find numerous examples of reference to the notion of relations, so it is by no means a new concept, previously absent in academic discourse. A rich research tradition, together with the dominance of substantial optics in the exploration of social life, has caused the notion of relationship to be undervalued in the field of sociology. Consequently, the relational nature of reality has not been sufficiently perceived. Modernist heritage, in the form of the idea of an autonomous entity or as an opposition to this idea-the vision of society as a spontaneous entity determining human activity-has clearly defined the subject of cognition in the social sciences. However, the weakness and limited exploratory power of thinking in terms of subject-object, micro-macro, or agency-structure dichotomies has been shown. The main dilemma faced by contemporary sociological theory has been reduced to a choice between two perspectives: substantialist and relational. The relational turn, which is currently taking place in social theory, leads to the redefinition of the subject of cognition. Reality ceases to be understood in a static and reified manner, in turn revealing itself in the weave of dynamic relations. Relationality as the fundamental dimension of reality has come to be situated at the centre of theoretical and research interests. Adoption of the thesis on the inherently processual and relational nature of reality has important cognitive consequences. The emphasis placed on the relational and processual nature of all dimensions of social life is perceived as a chance to transcend the individual-society dualism, which previously caused a theoretical impasse.

The postulate of abandoning the substantive conception of reality is clearly formulated in all varieties of the relational turn. The relational ap- 
proach, in all its diversity, pushes for a new way of defining reality, recognizing relationships as its foundation. Recognition that each entity arises from relations all beings emerge from a relationship means adopting a new ontology, and consequently leads to specifying new epistemological theses. Ontological questions play a leading role in sociological debates announcing the arrival of a new paradigm. In the context of the questions posed, there is a clear disagreement between social constructivism and critical realism, which generates serious divisions among supporters of the relational approach. ${ }^{4}$ Different ontological assumptions make society appear either as an objective and emergent layer of reality, or as a negotiable social construct. Opposition to the substantial understanding of the human self and the emphasis placed on its relativity can equally well lead to affirmation of constructionism, as well as to defense of a realistic ontology. The conceptions of identity that have been presented, and that provide different ways of describing an individual, illustrate the lack of agreement in this regard.

The internal diversification of relational sociology shows how relations can be differently conceptualized and is a good reflection of the divergence in the role they play in the creation of identity. The general difference comes down to how the human being and its self are understood in the context of socialization. The origin of the human self is embedded in the social praxis but also in various forms of social conversation. In the first case, the human consciousness and sense of self is born in social practice and is pre-discursive, whereas in the second, the self is a discursive effect of socialization. Language as a product of socialization competes with experience gained in practical action. We are therefore faced with two very different approaches. This raises the question of the role of language in the creation of the human self. Are linguistic competences acquired in the process of socialization a necessary condition for the development of the human self? Or is it rather the opposite, since the ability to use language presupposes the existence of the self? Although in the field of relational sociology theories answering both versions of this question have been developed, it must be emphasized that the effects of this research may be differently assessed. It seems premature in this context to downplay social practice in favour of discursive consciousness; moreover, prioritizing language goes

\footnotetext{
4 In a relatively new study on relational sociology, François Dépelteau points to the existence of three major divisions as a result of accepting a different ontology: deterministic (or structuralist) relational sociology, co-deterministic (or dialectical) relational sociology, and "deep" relational ontology (Powell \& Dépelteau 2013).
} 
hand in hand with underestimation of the role of emotions in the process of identity-formation.

Affirmation of the relational perspective also leads to reflection on the adequacy of the methodological assumptions and procedures adopted in sociological research. In this case, the subjects of research are not the objects of the social world but the networks of their interconnections and dependencies. In seeking to understand the dynamic aspect of social reality, relationally-oriented sociology tries to capture the subject of its research in action. As a result, reflection on reality is a judgment about the processes that constitute it, and cognition of reality is based on showing its social relations, which are variable in time and space. Therefore the task of sociology is not to determine or challenge the existing state of things, nor even to give an answer as to why it is as it is, but reflexively to monitor what is happening, and to recognize the processes that make up the matter of the social world. Such a research attitude encounters considerable difficulties, because the concepts by which we describe reality are much more suited to naming states than processes.

Relational sociology breaks up the schemes of theoretical thinking that in a highly individuated way conceptualize the human being as an autonomous self. Gergen's social constructivism leads to the complete abolition of this optics, identifying the human self as a network of social relationships. The multiphrenic self reveals only its inner contradiction and appearance. The individual disappears in a world of relationships that it has lost control of. If we agree with this statement, the notion of identity as a derivative of the human self loses its legitimacy and becomes, according to the terminology of Ulrich Beck, an unnecessary "zombie" concept. People become the tales they are making for the moment, and their identity is only a linguistic construct, a cultural artifact. Both Archer and Donati strongly oppose Gergen's views. For them, the relational approach to the individual does not lead to the blurring of the human self, and consciousness, as prior to social relations, is not reduced only to them. The reflexivity that manifests itself in the inner conversation, defined as the differentia specifica of humanity, is a counterbalance to the immensity of participation in social relations. This is an attempt to restore the category of subject, which has been heavily undermined by anti-humanist postmodernist theories. In the approach Archer and Donati propose, a human being, treated as a relational subject, gains the capacity for creative, subjective action through a relationally formed identity, both personal and social. 
The relational approach to identity research emphasizes the role of reflexivity as a distinguishing feature of the human person. Reflexivity has a relational basis, both internally as a dialogical self and externally, through contact with the wider environment in which the individual lives. It is stimulated by the actual experience of the individual - a network of relationships and social practices, all of which interact mutually and play a major role in the formation of identity. Reflexivity, as the basic material of the human self, allows for the narrative formation of oneself and the world (Gergen, Somers), or, in the form of inner conversation, is the medium between human agency and the structural context (Archer, Donati). The fundamental difference between these two ways of describing the human self is a different perception of the role of language in the process of shaping the human self. A relational approach defining identity as narration assumes the primacy of language over experience. On the other hand, Archer and Donati, as critical realists, accept the opposite thesis, that people build their sense of self in the social praxis. Although emphasizing that the narrative character of identity is not doubted, it is worth remembering that the textualization of reality brings a lot of limitations and does not constitute a solution to the ontological disputes. Naming and categorizing reality has its price and brings social consequences, but the real world resists language and cannot be reduced to words. Moreover, respect for social practice also allows us to appreciate the importance of non-discursive knowledge in the process of knowing social reality. Differences between these two distinguished positions reflect well the tension associated with the theoretical debate about the role of social practices and language in the process of shaping the human subject. Furthermore, they make us realize that the way the late modern human condition is understood depends largely on the ontological theses adopted, and the resulting knowledge is not free from normative implications.

Bibliography:

/// Archer M.S. 2000. Being Human: the Problem of Agency, Cambridge University Press.

/// Archer M.S. 2003. Structure, Agency and the Internal Conversation, Cambridge University Press. 
/// Archer M.S. 2007. Making our Way through World: Human Reflexivity and Social Mobility, Cambridge University Press.

/// Archer M. 2013. Cžłowieczeństwo. Problem sprawstwa, transl. A. Dziuban, Zakład Wydawniczy Nomos.

/// Benton T., Craib I. 2003. Filozofia nauk spotecznych. Od pozytywizmu do postmoderniżmu, transl. L. Rasiński, Wydawnictwo Dolnośląskiej Szkoły Wyższej Edukacji TWP.

/// Donati P. 2011. Relational Sociology: A New Paradigm for the Social Sciences, Routledge.

/// Donati P. 2016. The 'Relational Subject' According to a Critical Realist Relational Sociology, "Journal of Critical Realism”, vol. 15(4), pp. 352-375.

/// Donati P., Archer M. 2015. The Relational Subject, Cambridge University Press.

/// Emirbayer M. 1997. Manifesto for a Relational Sociology, "American Journal of Sociology", vol. 103(2), pp. 281-317.

/// Emirbayer M. 2013. Relational Sociology as Fighting Words, [in:] Conceptualizing Relational Sociology. Ontological and Theoretical Issues, eds. Ch. Powell, F. Dépelteau, Palgrave Macmillan, pp. 209-211.

/// Gergen K.J. 1991. The Saturated Self: Dilemas of Identity in Contemporary Life, Basic Books.

/// Gergen K.J. 1997. Social Theory in Context: Relational Humanism, [in:] The Mark of the Social, ed. J.D. Greenwood, Rowman \& Littlefield Publishers, pp. 213-230.

/// Gergen K.J. 2006. The Relational Self in Historical Context, "International Journal for Dialogical Science", vol. 1(1), pp. 119-124.

/// Gergen K.J. 2009. Nasycone Ja. Dylematy toஷ்samości w ஷ்yciu wspótczesnym, transl. M. Marody, Wydawnictwo Naukowe PWN.

/// Gergen K.J. 2011. The Self as Social Construction, "Psychological Studies", vol. 56(1), pp. 108-116.

/// Powell Ch., Dépelteau F., eds. 2013. Conceptualiæing Relational Sociology: Ontological and Theoretical Issues, Palgrave Macmillan. 
/// Somers M.R. 1992. Narrativity, Narrative Identity, and Social Action: Rethinking English Working-Class Formation, "Social Science History", vol. 16(4), pp. 591-630.

/// Somers M.R. 1994. The Narrative Constitution of Identity: A Relational and Network. Approach, "Theory and Society", vol. 23, pp. 605-649.

/// Somers M.R. 1998. "We're Not Angels”: Realism, Rational Choice, and Relationality in Social Science, "American Journal of Sociology", vol. 104(3), pp. 722-784.

/// Wiley N. 2006. Pragmatism and the Dialogical Self, "International Journal for Dialogical Science", vol. 1(1), pp. 5-21.

/// Wiley N. 2010. Inner Speech and Agency, [in:] Conversations about Reflexivity, ed. M. Archer, Routledge, pp. 17-38.

\section{/// Abstract}

Relational sociology rejects substantialism and focuses its attention on the complexity and dynamics of all forms of social life and the subjective nature of action. Relational thinking is an alternative attitude to both functional structuralism and strongly individualistic-oriented theories. Relationality emphasizes the processual and emergent nature of reality. Actions - individual and collective — appear as successive stages of a specific process of events, and result from the configuration of relations and social interactions constituting a particular situation. Different conceptions of identity have been developed within relationally oriented sociology. The aim of the article is to summarize the narrative and realistic approaches, and to present how much they differ in their ontological assumptions. The constructionist concept of narrative identity presented by Margaret R. Somers, and Kenneth J. Gergen's project of a "relational self," illustrate the narrative approach. Pierpaolo Donati's concept of the relational subject and the theory of agency developed by Margaret S. Archer exemplify the position of critical realism.

Keywords:

relational sociology, dialogical self, identity, narrative, relational subject 
/// Irena Szlachcicowa- PhD, assistant professor at the Insitute of Sociology at the University of Wrocław. Her research interests are social theory, qualitative methodology, and the sociology of the borderland. Recent publications include Konwersacja wewnetrana a sprawstwo w perspektywie metodologii refleksyjnej [Internal Conversation and Agency in the Perspective of Reflexive Methodology] in Sprawstwo. Teorie, metody, badania empiryczne w naukach spotecznych (2013), O przekeraczaniu granic w konstruowaniu rzeczywistości spotecznej orazpróbach jej poznawania [Crossing the Boundaries of Social Reality Construction and Attempts to Explore It] in Granice i pograniczapaństw, grup, dyskursów...Perspektywa antropologiczna i socjologiczna (2013), Disappearing Borders and the Unbearable Lightness of Identity in Advances in European Borderlands Studies (2017).

E-mail: i.szlachcicowa@gmail.com 